\title{
Papers
}

\section{Influences on hospital admission for asthma in south Asian and white adults: qualitative interview study}

\author{
Chris Griffiths, Gurmit Kaur, Madeleine Gantley, Gene Feder, Sheila Hillier, Jill Goddard, \\ Geoff Packe
}

\begin{abstract}
Objective To explore reasons for increased risk of hospital admission among south Asian patients with asthma.

Design Qualitative interview study using modified critical incident technique and framework analysis. Setting Newham, east London, a deprived area with a large mixed south Asian population.

Participants 58 south Asian and white adults with asthma (49 admitted to hospital with asthma, 9 not admitted); 17 general practitioners; 5 accident and emergency doctors; 2 out of hours general practitioners; 1 asthma specialist nurse.

Main outcome measures Patients' and health professionals' views on influences on admission, events leading to admission, general practices' organisation and asthma strategies, doctor-patient relationship, and cultural attitudes to asthma.

Results South Asian and white patients admitted to hospital coped differently with asthma. South Asians described less confidence in controlling their asthma, were unfamiliar with the concept of preventive medication, and often expressed less confidence in their general practitioner. South Asians managed asthma exacerbations with family advocacy, without systematic changes in prophylaxis, and without systemic corticosteroids. Patients describing difficulty accessing primary care during asthma exacerbations were registered with practices with weak strategies for asthma care and were often south Asian. Patients with easy access described care suggesting partnerships with their general practitioner, had better confidence to control asthma, and were registered with practices with well developed asthma strategies that included policies for avoiding hospital admission.

Conclusions The different ways of coping with asthma exacerbations and accessing care may partly explain the increased risk of hospital admission in south Asian patients. Interventions that increase confidence to control asthma, confidence in the general practitioner, understanding of preventive treatment, and use of systemic corticosteroids in exacerbations may reduce hospital admissions.

Development of more sophisticated asthma strategies by practices with better access and partnerships with patients may also achieve this.
\end{abstract}

\section{Introduction}

Black and south Asian people are at increased risk of hospital admission with asthma. ${ }^{1-7}$ Analysing 15921 admissions, Gilthorpe reported higher age standardised admission rates for black and south Asian patients compared with white patients, with excess risk only partially attributable to socioeconomic status. ${ }^{5}$ In Birmingham and Blackburn respectively, Ayers and Ormerod found that risk of admission for south Asian adults was more than double that for white adults. ${ }^{24}$ Despite these findings, no consistent differences in severity or prevalence of asthma, prescribed drugs, or asthma education have been described. ${ }^{148}$ In one study south Asian patients were less likely to report adherence to their drug regimen or self management behaviour. ${ }^{1}$ Interventions to reduce admission rates in black and Asian groups have met with variable success. ${ }^{9-11}$

Differences in hospital admission rates for asthma between ethnic groups might be because of differences in beliefs or behaviour during exacerbations or in access to or delivery of care. Our aim was to explore these factors in south Asian and white adults admitted to hospital with asthma.

\section{Participants and methods}

The study setting was Newham, east London, a highly deprived area with a large $(30 \%)$ mixed south Asian population (Indian, Pakistani, and Bangladeshi). ${ }^{12}$ The local research ethics committee approved the study.

\section{Participants}

Patients admitted with asthma-We recruited 49 south Asian and white adults admitted with acute asthma to Newham General Hospital (see box 1 for details). Recruitment was, as far as possible, consecutive (an intensity sample).$^{13}$ We identified patients on hospital wards, verified diagnoses in records, and asked patients to name their usual general practitioner. As recruitment proceeded, we reviewed the sample to ensure maximum diversity of experience in terms of age, ethnicity, religion, duration and management of asthma attack, and route of hospital admission. The diversity of south Asian groups in Newham was reflected in the sample.
Department of
General Practice
and Primary Care,
St Bartholomew's
and the Royal
London School of
Medicine and
Dentistry, Queen
Mary's School of
Medicine and
Dentistry, London
E1 4NS
Chris Griffiths
reader in primary
care
Gurmit Kaur
researcher
Madeleine Gantley
senior lecturer
Gene Feder
professor of primary
care research and
development
Department of
Human Science
and Medical Ethics,
Royal London
Hospital, London
E1 2AD
Sheila Hillier
professor of medical
sociology
Newham General
Hospital, London
E13 8RU
Jill Goddard
asthma specialist
nurse
Geoff Packe
consultant chest
physician
Correspondence to:
C Griffiths
c.j.griffiths@mds.
qmw.ac.uk 
Box 1: Details of 58 south Asian and white patients interviewed

Age

- Mean 45 years (range 17-72)

Sex

- 39 women, 19 men

Ethnicity (allocated by researcher during interviews)

- 24 south Asian-9 Pakistani Muslims, 5 Punjabi Sikhs, 3 Gujarati Muslims, 1 Indian Muslim, 2 Punjabi Hindus, 1 Gujarati Hindu, 1 Sri Lankan Hindu,

1 Bangladeshi Hindu, 1 Keralan Hindu

- 34 white

Medication (British Thoracic Society (BTS) step ${ }^{13 a}$ )

- Step 1 (2 patients), steps 2-3 (38), step 4 (14), step 5 (4)

Patients not admitted to hospital-Since the patients admitted to hospital might be atypical in terms of their asthma management, we compared their experiences with those of a limited number of patients with severe asthma (British Thoracic Society (BTS) step $\geqslant 3^{13 a}$ ) but who had avoided admission. We identified these nine dissonant $\operatorname{cases}^{13}$ in the hospital asthma clinic and a general practice (box 1).

General practitioners-Initially we interviewed a maximum variety sample ${ }^{13}$ of patients' general practitioners from practices with high and low admission rates for asthma, and from singlehanded and group practices. As recruitment proceeded, we extended sampling to include practices where patients described particularly good or poor relationships with their doctors. In total, we interviewed 17 general practitioners from six singlehanded, four two-partner, and six group practices.

Hospital clinical staff and out of hours primary care services-We identified hospital and out of hours factors that might influence admission by interviewing five doctors from Newham accident and emergency department, the hospital asthma specialist nurse, and two doctors working for the local Healthcall organisation.

\section{Interviews}

With their informed consent, GK interviewed patients in their chosen language (variously Punjabi, Hindi, Urdu, Gujarati, and English), usually on hospital wards. A topic guide covered experiences of admission and contributing factors, coping with asthma, causes of exacerbations, and relationships with clinicians (appendix). Interviews were taped, translated where necessary, and transcribed verbatim. CG interviewed the general practitioners, covering events leading to admission, their knowledge of the patient, and practice strategies for managing asthma (appendix).

\section{Data analysis}

We modified the critical incident technique ${ }^{14}$ to include elements of the framework approach, ${ }^{15}$ allowing analysis of interplay of identified factors. A multidisciplinary team (sociologist, anthropologist, and primary and secondary care doctors) met regularly to analyse data. Two researchers coded interviews independently before entry on a database. We divided patients' transcripts into six narrative threads, a category summarising influences on admission, and events leading to admission. We divided general practitioners' transcripts into practice organisation, asthma strategy, doctor-patient relationship, cultural attitudes to asthma, and events leading to admission. We generated a list of influences on admission mentioned, akin to the product of the original critical incident method.

We cross tabulated patients' and doctors' transcripts to identify emerging themes and developed charts exploring these and others important to the researchers. We explored differences between south Asian and white patients and their access to care using charts that cross tabulated transcript data, the patients' asthma severity, duration of exacerbation, and practices' hospital admission rates for asthma.

\section{Results}

We identified 60 influences on hospital admission, illustrating the complexity of participants' experience (table). Patients' statements about cognition, education, and behaviour were striking for their strength or consistency across and within interviews. We present data in three sections-personal influences, health professional influences, and access to primary care.

\section{Personal influences}

Patients described asthma attacks ranging from severe acute episodes causing immediate admission to exacerbations lasting weeks. As well as citing causes such as infections and pollution, many patients described adverse social circumstances and reckoned stress a cause of attacks-"I am here about nine years now, and they are saying that 'You have to go' [be deported]... That's why I'm really stressed... That may be the cause" (34 year old Bangladeshi Hindu man).

Confidence to control asthma differed between the two patient groups. Many south Asian patients talked in passive terms about controlling asthma and dealing with attacks-"What do you do to control your asthma? Nothing really. Just salbutamol isn't it" (34 year old Bangladeshi Hindu man)-with relatives managing attacks on a patient's behalf or acting as mediators. Some statements by south Asian patients seemed resigned-"The illness is here, it was going to happen" (45 year old Pakistani Muslim woman)-suggesting a particular attitude to illness in general and their response to it. Many white patients seemed more personally proactive and spoke of control in the first person (box 2).

Poor understanding of the roles of asthma drugs occurred in both groups but was widespread among the south Asian patients-"Pumps, there are so many different ones-blue, brown, green-I put the machine on as well. I don't know what is happening" (60 year old Punjabi Hindu woman). In particular, the concept of preventive medication was described by only one south Asian patient (who used only salbutamol) but was familiar to white informants. One white man illustrated his understanding by drawing a distinction between drugs for headaches and those for asthma (box 2). Although reference to formal management plans were rare, white patients frequently described increasing the use of a corticosteroid inhaler during an attack; this was absent from south Asians' accounts. Sole use of reliever inhalers or nebulisers or non-specific use of 
Frequency of influences on hospital admission extracted from interviews with 51 patients admitted to hospital with asthma and 17 of their general practitioners

\begin{tabular}{|c|c|}
\hline Influence & Total \\
\hline Poor understanding of self management skills & 31 \\
\hline Belief that hospital is best place to be treated & 25 \\
\hline Confidence in general practitioner & 23 \\
\hline Simple access to general practitioner & 16 \\
\hline Poor understanding of how medication works & 15 \\
\hline Family support & 14 \\
\hline Confidence in control & 14 \\
\hline Lack of confidence in general practitioner & 14 \\
\hline Good adherence & 14 \\
\hline Stress & 13 \\
\hline Poor adherence & 13 \\
\hline Passive or resigned perspectives & 12 \\
\hline Understands action of medications & 11 \\
\hline Failure to diagnose asthma exacerbation or prescription of antibiotics & 10 \\
\hline Severe asthma & 9 \\
\hline Understands medical self management behaviour & 8 \\
\hline Comorbidity—physical & 7 \\
\hline Comorbidity—mental & 7 \\
\hline Brittle asthma—sudden onset & 7 \\
\hline Poor access-general practitioner won't visit & 7 \\
\hline Good general practice asthma strategy & 7 \\
\hline General practice has an asthma clinic & 7 \\
\hline Poor access to out of hours care, patient did not try to call & 7 \\
\hline No asthma clinic & 6 \\
\hline Continuity of care & 5 \\
\hline Stress-family illness & 4 \\
\hline Delayed calling general practitioner as believed could manage alone & 4 \\
\hline Failure to prescribe oral corticosteroids & 4 \\
\hline Does not attend specialist clinic & 4 \\
\hline Uses home nebuliser & 4 \\
\hline Attends specialist clinic & 4 \\
\hline General practitioner asks to review before prescription given & 4 \\
\hline No proactive asthma care (strategy) by general practitioner & 4 \\
\hline Poor access to general practitioner-can't get appointment & 4 \\
\hline Oral corticosteroids begun by general practitioner & 3 \\
\hline General practice has no nurse & 3 \\
\hline Poor continuity of care-locum doctor & 3 \\
\hline Poor access to general practitioner & 3 \\
\hline Poor access-out of hours service declines to visit & 3 \\
\hline Poor access to general practitioner out of hours & 3 \\
\hline Poverty & 2 \\
\hline Lives far from general practice & 2 \\
\hline Undertreatment & 2 \\
\hline Poor trust of general practitioner-cost cutting & 2 \\
\hline Language not a problem & 2 \\
\hline Not seeing patient before prescribing & 2 \\
\hline Out of hours doctor tells patient to go to hospital & 2 \\
\hline Lack of family support & 1 \\
\hline Hates idea of being in hospital & 1 \\
\hline $\begin{array}{l}\text { Poor access to general practitioner-patient can't come in because of } \\
\text { working hours }\end{array}$ & 1 \\
\hline General practitioner seeks to review regularly & 1 \\
\hline General practitioner treats asthmatic patients in the surgery & 1 \\
\hline No review before routine treatment & 1 \\
\hline Lack of defined role for nurse & 1 \\
\hline Asthma not a priority for the practice & 1 \\
\hline Failure to prescribe oral corticosteroids for home use & 1 \\
\hline No health visitor & 1 \\
\hline Not knowing patient-temporary resident & 1 \\
\hline Poor continuity of care-group practice & 1 \\
\hline Healthcall slow to visit & 1 \\
\hline
\end{tabular}

many inhalers was described by some white patients but by all the south Asians interviewed.
Box 2: Personal influences on asthma control among south Asian and white patients

Controlling asthma and coping with exacerbations

"I can't do anything on my own will."

What do you do to control [your asthma]? "I go to my daughter's." What does your GP say about your illness? "He says, 'I will treat, have faith in God."

49 year old Punjabi Hindu woman

When you get an asthma attack what do you do? "I don’t do anything, I come here ... You telephone, and the ambulance comes."

60 year old Punjabi Hindu woman

"I had a bad attack, probably three years ago, and then I stopped smoking and I've completely changed my life around. But since then I've managed my asthma better than I ever have done, you know."

32 year old white man

Concept of asthma prevention medication

What do you do to control it? "Ventolin."

Do you use any other one? "I have the brown but I only use the blue one."

How long have you had the brown one? "I don't have the date-two or three years."

Do you know what the two medicines do? "That one [brown] you don't have an attack the doctor told me."

40 year old Pakistani Muslim woman

"Half of these medicines they give you here for asthma, you've got to take them on a regular basis ... Becotide, now that's a preventative ... you're supposed to use that all the time, you can't just use that and think, 'I've got an attack coming on, I'd better use it.' It's too late ... take like an 'eadache, where you think, 'I'll take a tablet for me 'eadache and it'll get rid of it.' With asthma, I think asthma's an illness on its own, you've got to keep your airwaves [airways] open all the time"

58 year old white man

Concept of systemic corticosteroids in asthma exacerbations

"I took a big dose of steroids because that is how I have been told to handle it."

45 year old white woman (a)

"Cortisone or something, that is one wonderful thing. That is something out of this world because within 20 minutes you think, "cor that's good stuff, I can breathe again."

58 year old white man

Confidence in general practitioners

"He's brilliant. He's got an asthma nurse, he's got a diabetic clinic ... he knows all my history ... He seems to have more time because he knows you better."

60 year old white woman (a)

"When the medicine I need I go there, and if I have a big problem I go there, but my GP doesn't help much, he doesn't help me in many things now." 60 year old Keralan Hindu man

The concept of using systemic corticosteroids to abort an exacerbation was mentioned by only one south Asian man (his general practitioner declined his request) but was common among the white patients interviewed. Some started corticosteroid tablets at home, and others contacted their general practitioner urgently to obtain them. One even sought intravenous steroids-"When I'm really bad, like, I go to the doctor's. He puts it in the vein, and it goes through the bloodstream quicker" ( 55 year old white woman).

Patients often held extreme views of their general practitioners. Although patients from both ethnic groups had experience of doctors they felt were inadequate-"He's a bitch. He's useless. He's too busy, he says. He works two hours in the morning and two hours in the evening surgery" (60 year old white woman (b))-overall there were qualitative differences in relationships with general practitioners. Some white 
informants said how long they had been registered with the same doctor and that they were on first name terms-"He knows me so well" (55 year old white woman). They valued continuity and personal care"He's the man who's looking after me, you know" (65 year old white man (a)). This familiarity was not evident in the accounts of south Asian patients, whose statements were less personal-"He is neither good nor bad. He is 50:50" (45 year old Pakistani Muslim man)and more functional, for example, that their general practitioner spoke the same language, would visit if necessary, or might telephone to check they were well.

Although there were some similarities in lifestyle and use of complementary asthma treatment by patients (such as relaxation techniques, homoeopathy, Chinese herbalism, home acupuncture kits), there were important differences. Some south Asians used traditional medicines or dietary changes consistent with Islamic or ayurvedic humoral systems, particularly hot food spices such as ginger or turmeric, reflecting a view that cold foods were a cause of asthma. These were used in addition to, and rarely instead of, Western drugs. By contrast, white patients mentioned self help (helplines, videos, and books), lifestyle changes (stopping smoking, avoiding passive smoking, exercise, recreation, taking vitamins), and peak expiratory flow monitoring.

\section{Patients with severe asthma who had not been admitted to} hospital

Both white and south Asian patients who had avoided admission talked confidently about controlling asthma, understood the concept of preventive medication, and trusted their general practitioner or the local asthma specialist nurse-"The consultant [specialist] nurse at the asthma clinic, she's been very helpful, saying 'Well if you've got a bad attack you can take $\mathrm{X}$ amount dosage of salbutamol' and things like that" (42 year old white woman). Support from relatives generated control and confidence, rather than simply having someone to mediate. Most patients had confidence to experiment with self care. The medical model of self management was common (box 3).

\section{Health professional influences}

General practitioners'attitudes towards self management and systemic corticosteroids

Self management plans were seen by general practitioners as impractical, the level of understanding required being beyond most patients. Many were wary of using systemic corticosteroids - "I don't use courses of steroids, for the simple reason ... I just leave them to the hospital" (general practitioner of 57 year old Gujarati Muslim woman)-let alone allowing patients the responsibility to use them at home. One patient said: "He made me sign; he said, 'You are taking steroids,' and he wrote a letter and put paper and said, 'Sign here.' I didn't know, then afterwards he read out what he made me sign. He said, 'You are taking steroids out of your own will. If there is an effect then there will be no action against me.' This is my GP" (65 year old Punjabi Sikh woman).

Views of accident and emergency doctors

Accident and emergency doctors asserted that patients were admitted on the basis of clinical severity
Box 3: Confidence to control asthma in south Asian and white patients with asthma not admitted to hospital

Being positive

"I think you have got to be positive. It is no good sort of, you've really got to be positive in the outlook, and you've got to actually think to yourself, 'Well, I'm in control."”

42 year old white woman

Partner generating confidence to control asthma What role did your partner play? "He was very, very good. He was so caring. He went through the stages with me, made me do my breathing exercises, was there anything he could do or fetch, he helps me through it."

Do you change your medication? "Yes, it all depends on how I feel. If I wake up in the morning bad, right, and my peak flow is low then I take my steroid inhaler $500 \mu \mathrm{g}$, and I take two puffs of that. Then I take my Ventolin about 10 minutes afterwards. Then I take six steroid tablets, that is only if it is bad."

45 year old white woman (b)

alone-"Well, I don't know much about people's backgrounds when they come in. I haven't got a lot of time to get into their social history ... My two biggest [criteria] are pulse and respiratory rate" (accident and emergency senior house officer).

\section{Access to primary care during asthma attacks}

Easy access to primary care

Patients gaining easy access to primary care during exacerbations described good relationships with their general practitioners. White patients predominated in this group; they had confidence to control asthma and were proactive, negotiating contact with primary care themselves and rarely involving relatives. The urge to contact their general practitioner (rather than go straight to hospital) was reinforced by previous experience-"I prefer going to my GP ... you know because he wants to see me" (20 year old white woman).

General practitioners described well developed and sometimes elaborate strategies for asthma care and gave examples showing why they saw asthma as a priority (box 4). Admission avoidance policies were common, including targeting high risk patients, offering "privileged access," and providing out of hours continuity of care. These policies were reflected in the partnerships doctors developed with patients, sometimes over years, in which they encouraged and worked with patients to improve control-"Well I have known her, in my list, since 1982. [I] look at all the histories, I made a note: 'Father is asthmatic, child as an infant had eczema' ... I made a diagnosis of bronchial asthma." (Interviewer) So you made the original diagnosis? "In 1983-we go back quite a long time" (general practitioner of 20 year old white woman).

"When I started with him, giving up [smoking] was the major issue." (Interviewer) How would you describe your relationship with this chap? "I sponsored him [to run a marathon] ... I'd say I have a fairly good relationship with him" (general practitioner of 32 year old white man). 


\section{Difficult access to primary care}

Patients describing difficult access to primary care during asthma attacks were registered with practices with high admission rates for asthma (median admission rate 55th of 67 Newham practices, compared with 14th for easy access group). Most such patients were south Asian. Difficulties included the doctor declining to visit, telling the patient to arrange admission themselves, or giving telephone advice or a prescription in place of a face to face consultation, and a receptionist preventing patients speaking to their doctor. Family members (including children) either mediated contact with the general practitioner or were consulted as an alternative (box 4). General practitioners described basic asthma strategies, with regular review as a basic aim, but without prioritising asthma, targeting high risk patients, or referring to partnerships of care. A lack of nursing support for some practices led to a sense of desperation-"Our practice nurse has gone. I can only do [anything] when they come and sit in front of me-if they come. If they don't come I'm helpless" (general practitioner of 57 year old Gujarati Muslim woman).

\section{Direct self referral to hospital}

Patients in this group had exacerbations of more sudden onset (median duration of attacks before admission 2.5 days, with many admitted within 24 hours, compared with 7 and 14 days respectively for groups with easy and difficult access to primary care). White and south Asian patients called ambulances to get immediate care. Many had previous admissions and considered hospital to be the best place to be, and some had experience of poor access to primary care (box 4). General practitioners of these patients mostly described basic practice asthma strategies.

\section{Discussion}

This study takes a patient orientated rather than biomedical approach to understanding hospital admission for asthma. In comparing two ethnic groups we do not cast the behaviour of the white patients as normative. Indeed, few patients typified the medical model of asthma self management. We are aware of dangers of stereotyping behaviour in ethnic groups, as well as problems in aggregating groups into classifications that may obscure cultural differences. None the less, distinctions emerged in accounts of south Asian and white patients that are consistent with other work $^{116}$ and which could explain differences in risk of admission.

South Asian and white patients admitted with asthma differed in their confidence to control asthma, their understanding and use of medication, and their confidence in their general practitioners. The patients (frequently white) with confidence to manage exacerbations had good access to general practitioners with well developed practice strategies for managing asthma. These strategies emphasised policies to avoid admission, targeting of high risk patients, and a supportive approach. Good access to primary care is associated with reduced risk of hospital admission. ${ }^{17}$ Our findings are consistent with those of Clarke et al, who reported that a behavioural intervention for doctors that promoted a partnership style of consulting increased patients' confidence and reduced their use of
Box 4: Access to care during asthma attacks and practices' asthma strategies

Patients experiencing easy access to primary care

Doctor and practice nurse develop partnership with patient

"We [the practice nurse and GP] work with her."

General practitioner of 60 year old white woman (a)

Doctor describes partnership with patient and provides privileged access

"[She] would not see any doctor. I say, 'Anytime you've got a problem with your breathing, coughing, whatever, you ring me anytime, and I'll pop in to see you. Even if I'm not on duty I'll see you.' Gave her all the talks about asthma, literature about asthma, things about asthma, inhaler technique, checking peak flow. Gave her a peak flow meter she monitors. Tell her about the danger signals, about asthma, what she should ask for medical-wise ... She has a nebuliser at home, [which] has stopped few referrals to the casualty and few 999 calls. Given a course of steroids, which leave at the house in case. If she starts, she needs to start, so I just give her one dose, 'So you start it by the time I see you, because I don't want you to wait for appointment."

General practitioner of 20 year old white woman

Systematic approach targeting high risk patient to prevent admission

"It's impossible to have a structured approach with her, but that's what we've tried to do ... She's unmanageable otherwise. We don't want her to go back into hospital, so one of the partners says, 'It's my turn to take her on,' so they would visit her regularly to pre-empt hospital admission."

General practitioner of 50 year old white woman

"I've got three GPs. [They're] marvellous."

They're good? "Yes."

You're very happy with them? "I can't fault them."

50 year old white woman

Patients experiencing difficult access to primary care

Doctor declines to see patient and writes prescription instead

"No, the doctor is moody, sometimes he says come and other times not. My husband says, 'What kind of doctor is he?' The doctor said, 'We do not have an appointment, but I will write a prescription."”

34 year old Gujarati Muslim woman

Receptionist prevents access to general practitioner, out of hours service asks child to arrange ambulance

"I said to the secretary, 'Let me speak to the doctor.' She said the doctor is busy. I told her this was the problem and maybe he give the right medicine. Maybe she told the doctor what the problem was. The prescription was already written for me. I showed the prescription to the doctor. I told him, 'I have an asthma attack-I feel it might come on-I already have the flu.' I knew it was not right, not seeing my doctor. I found it difficult to control my breathing. I kept ringing every half an hour. Then I told the child to ring the emergency doctor. He said, 'There is no reason to come, I will not be able to find the right medicines for you so ring the emergency and go to hospital."'

45 year old Pakistani Muslim man

Asthma not prioritised,patients not targeted

Self management plans-do you use those very much for your patients? "Something I push for diabetes, but not for asthma."

Do you have any particular patients that you regard as high risk, that are different from your other patients? "Not high risk, no."

General practitioner of 34 year old Gujarati Muslim woman

Patients going directly to hospital, or lay mediated referral to hospital Rapid attention from hospital staff

"You get full attention once you come in [to hospital] with the breathing. You know you don't wait about anywhere. You're in-boomf-and you're sorted. It's wonderful."

65 year old white man (b)

Experience of slow response by general practitioner

"The GP actually takes a long time to deal with it. If I thought the GP was going to be quicker and they were able to deal with it better, I would have called them, I don't really like to come into hospital ... I had a kidney stone last year, and I phoned the GP to come ... After three hours they had not returned the call, so I called the ambulance... If you are going to wait three hours and you are having an asthma attack, you could not possibly do that." 45 year old white woman (a)

health services. ${ }^{18}$ Developing partnerships with doctors that lead to better asthma control might be more diffi- 
cult for some south Asian patients, either because doctors' espousal of Western medical concepts (such as use of regular prophylaxis) may impede a partnership relationship or because the partnership model itself may conflict with beliefs about what is an appropriate doctor-patient relationship.

Patients' descriptions of their confidence to control asthma bear some similarity to the concepts of self efficacy in social-cognitive theory and patient enablement. ${ }^{19}{ }^{20}$ Self efficacy describes an individual's confidence to carry out an activity and is a good predictor of success in self care initiatives. ${ }^{21}$ The south Asian patients admitted to hospital in this study were often less confident, even resigned, about controlling asthma compared with the white patients. This could reflect either an intrinsic cultural characteristic or the difficulties of coping with asthma in deprived social circumstances where racism is common and health services are often inadequate and inappropriate. Two observations support the latter view. Firstly, south Asian patients occasionally contrasted their poor asthma control in Britain with better control in India or Pakistan. Secondly, the south Asians and white patients we interviewed who had not been admitted showed similar confidence to control asthma and to experiment with new approaches.

\section{Understanding and use of asthma drugs}

Use of systemic corticosteroids and self management education reduce the risk of hospital admission with asthma. ${ }^{22}{ }^{23}$ That south Asian (and some white) patients seemed unaware of the roles and benefits of systemic corticosteroids and preventive treatment in exacerbations clearly made admission more likely. Moudgil et al reported that an educational intervention provided by a south Asian respiratory specialist reduced use of healthcare services for asthma in white but not south Asian patients, ${ }^{11}$ suggesting differences in how the same information is understood and acted on. Further work should determine how cultural barriers between patient and clinician hinder education.

\section{Other factors}

Although our sample was small, our study suggests some factors may be less important than previously thought. Firstly, language problems were rarely cited. Many south Asians in Newham have a good command of English and some local general practitioners speak Asian languages. Difficulties of access probably relate to a range of factors including organisation and attitudes within primary care as well as power issues between general practitioners, staff, and patients in areas such as race, class, religion, and sex. Secondly, singlehanded practices were capable of sophisticated asthma care, provided they were adequately resourced. Thirdly, south Asian patients referred themselves to hospital with similar reasons and frequency as white patients. Fourthly, use of traditional medication by south Asian patients was by no means ubiquitous and rarely to the exclusion of Western drugs. Fifthly, we found no evidence of an "ethnicity filter" at the accident and emergency department that might increase the likelihood of admission for south Asians. Sixthly, we found no difference in socioeconomic status that might explain differences between our two groups. Seventhly, we did not detect a gradient in control and confidence reflecting first to third generational status

\section{What is already known on this topic}

South Asian patients with asthma are at increased risk of hospital admission with asthma compared with white patients

No consistent differences in severity or prevalence of asthma, prescribed drugs, or asthma education have been described, and interventions to reduce admission rates in Asian patients have met with variable success

\section{What this study adds}

Compared with white patients, south Asian patients admitted to hospital with asthma had less confidence to control asthma, were unfamiliar with the concept of preventive medication, and had less confidence in their general practitioners

South Asian patients managed asthma attacks through family advocacy and without systematic changes in prophylaxis and without systemic corticosteroids

Patients reporting difficulty in accessing primary care during attacks were often south Asian

of south Asians. Finally, we found no evidence of variations in behaviour between south Asian groups.

We increased the validity of our analysis with several methods. We constantly compared new with existing data ${ }^{24}$ and sought dissonant cases. We gathered data from a range of sources, and we interviewed in first languages to avoid using interpreters. Use of a multidisciplinary group made some allowance for the possible influences that researchers' backgrounds might have on the analysis. Two researchers coded interviews independently to enhance consistency. We triangulated qualitative data with quantitative data on general practices' hospital admission rates.

\section{Conclusions}

General practices with south Asian patients may benefit from interventions that encourage the development of sophisticated asthma strategies including admission avoidance policies and partnership styles of consultation. A better understanding of the meaning of asthma in south Asian groups should contribute to educational interventions that promote the concepts of preventive treatment, self care, and the benefit of systemic corticosteroids.

We thank all the participants; Patricia Sturdy, Ian Jones, and Keith Meadows for help developing the original idea; Jeannette Naish for advice on sampling and help identifying patients; Dorcas MacLaren for providing practice admission rates; Tanya Price and Mei Chung for administrative support; and Colin Bradley for observations on the use of the critical incident technique.

Contributors: CG conceived and designed the study, interviewed general practitioners, and wrote the first draft. SH and GF contributed to the initial design. MG provided methodological development and review of sampling, data collection and analysis. GK interviewed patients, translated and coded transcripts, and developed the database. All authors contributed to analysis and revisions of the paper. CG is the guarantor for the study.

Funding: The National Asthma Campaign.

Competing interests: None declared. 
1 Moudgil H, Honeybourne D. Differences in asthma managemen between white European and Indian subcontinent ethnic groups living in socioeconomically deprived areas in the Birmingham (UK) conurbation. Thorax 1998;53:490-4.

2 Ayres JG. Acute asthma in Asian patients: hospital admissions and duration of stay in a district with a high immigrant population. $\mathrm{Br} J$ Dis Chest 1986:80:242-8

3 Myers P, Ormerod LP. Increased asthma admission rates in Asian patients: Blackburn 1987. Respir Med 1992;86:297-300.

4 Ormerod LP. Adult Asian acute asthma admission rates reassessed: Blackburn 1991-1992. Respir Med 1995;89:415-7.

5 Gilthorpe MS, Lay-Yee R, Wilson RC, Walters S, Griffiths RK, Bedi R. Variations in hospitalization rates for asthma among black and minority ethnic communities. Respir Med 1998;92:642-8.

6 DePalo V, Mayo PH, Friedman P, Rosen MJ. Demographic influences on asthma hospital admission rates in New York City. Chest 1994;106:44751.

7 Rona RJ. Asthma and poverty. Thorax 2000;55:239-44.

8 Partridge MR. In what way may race, ethnicity or culture influence asthma outcomes? Thorax 2000;55:175-6.

9 Kelso TM, Self TH, Rumbak MJ, Stephens MA, Garrett W, Arheart KL. Educational and long-term therapeutic intervention in the ED: effect on outcomes in adult indigent minority asthmatics. Am J Emerg Med 1995;13:632-7.

10 Sperber K, Ibrahim H, Hoffman B, Eisenmesser B, Hsu H, Corn B. Effectiveness of a specialized asthma clinic in reducing asthma morbidity in an inner-city minority population. J Asthma 1995;32:335-43.

11 Moudgil H, Marshall T, Honeybourne D. Asthma education and quality of life in the community: a randomised controlled study to evaluate the impact on white European and Indian subcontinent ethnic groups from socioeconomically deprived areas in Birmingham, UK. Thora 2000;55:177-83

12 East London and the City Health Authority. Health in the East End:annual public health report 1999/2000. London: East London and the City Health Authority, 2000.

13 Quinn Patten M. Qualitative evaluation and research methods. London: Sage, 1990.

13a British Thoracic Society. The British guidelines on asthma management: 1995 review and position statement. Thorax 1997;52(suppl):S1-21.

14 Bradley C. Turning anecdotes into data-the critical incident technique Fam Pract 1992;9:98-103.

15 Ritchie J, Spencer L. Qualitative data analysis for applied policy research In: Bryman A, Burgess RG, eds. Analysing qualitative data. London: Routledge, 1994

16 Community Health Sciences Research Group. Systematic reviews of access to and treatment of cardiovascular disease and mental health services in ethnic groups. London: Department of General Practice and Primary Care, Queen Mary College, 2000.

17 Bindman AB, Grumbach K, Osmond D, Komaromy M, Vranizan K, Lurie $\mathrm{N}$, et al. Preventable hospitalizations and access to health care. JAMA 1995;274:305-11.

18 Clark NM, Gong M, Schork MA, Evans D, Roloff D, Hurwitz M, et al. Impact of education for physicians on patient outcomes. Pediatric 1998;101:831-6.

19 Bandura A. Self efficacy. New York: W H Freeman, 1997.

20 Howie JGR. Quality at general practice consultations: cross sectional survey. $B M J$ 1999;319:738-43.

21 Conner M, Norman P. Predicting health behaviour. Buckingham: Open University Press, 1996.

22 Rowe BH. Effectiveness of steroid therapy in exacerbations of asthma: meta-analysis. Am J Emerg Med 1992;10:301-10.

23 Gibson PG, Coughlan J, Wilson AJ, Abramson MJ, Bauman A, Hensley MJ, et al. Self-management education and regular practitioner review for adults with asthma. Cochrane Database Syst Rev 2000;(2):CD001117

24 Green J. Commentary: grounded theory and the constant comparative method. BMJ 1998;316:1064-5

(Accepted 19 July 2001)

\section{Appendix: Interview topic guides}

\section{Interview topics for patients}

1. Access to general practitioner during an asthma attack

- Whom do you contact when you get a bad asthma attack, your GP or the hospital?

(Probe for relative ease/difficulty of access to GP $v$ accident and emergency department. Why might accident and emergency department be preferable?)

- Does distance from the GP surgery and distance from accident and emergency department make any difference?

- What would your GP do if you contacted them by phone during an attack?

(Probe for expectations of admission $v$ management in the community)

- Do patients have problems in receiving repeat prescriptions?
2. Opinions about site of best care

- Is your asthma attack better managed by the GP or in hospital?

(Probe for preferences, eg availability of nebulisers)

3. Choice of practice

- Why did you register with your practice?

(Probe for reasons relating to asthma care, such as clinics)

4. General asthma care in the general practice

- What does your doctor/practice provide especially for their asthma patients?

(Probe for reviews, clinics)

- Does the GP ever ask to see you before allowing a repeat prescription?

(Probe for unrestricted repeat prescribing)

\section{Health beliefs about asthma}

- What do you think caused your asthma?

- What do you think caused this asthma attack?

- What do you do when you feel an attack coming on?

- How do you know?

- How do you usually attempt to control your asthma?

- How typical/different was this last attack?

- What do the different medicines do to your body/breathing?

- Do they harm you in any way?

- Is it better to use tablets, injections or inhalers to control asthma?

(Probe for beliefs about medication use and traditional aetiologies and remedies)

- Is it better to take medicines for asthma regularly or only when you get an asthma attack?

(Probe for beliefs about medication use and adverse effects)

\section{Interview topics for general practitioners \\ 1. Issues relating to out of hours care}

- How are patients with acute asthma managed out of hours in your practice?

(Probe for degree of "aggressive" management such as carrying nebulisers, using oral corticosteroids) - How do you manage a call from a patient with an asthma attack?

(Probe for directive to attend accident and emergency department $v$ attend surgery $v$ home visit) - Do you routinely use a deputising service, a GP cooperative, or cover your own visits? How does your choice affect management of patients with acute asthma out of hours?

- What factors affect your threshold for referral of patients to hospital?

(Probe for potential for next day review in surgery by GP or partners/practice nurse)

\section{Attitude to and management of high risk asthma patients} in the practice

- Do you have any systematic methods of identifying and managing patients with bad asthma?

(Probe for tagging of notes/registers of admitted patients/targeted reviews/self management plans/ audits of severe asthma or use of nebulisers) 
3. General attitude to asthma management

- Do you feel you manage to cope with the workload presented by your asthma patients?

(Probe for excessive referral to hospital for clinics/ sense of "overload"/despair)

- What are the difficulties you face?

(Probe for views/beliefs about prevalence/poor housing/language difficulties)

4. GP views about their asthma patients

- Who do you see as the "experts" in asthma care?

- Who do your patients see as "experts" in asthma care?

(Probe for views of the "best place" to care for acute asthma)

- Are your patients good at assessing the severity of their asthma symptoms and understanding their asthma medication?

(Probe for differences between patients of differing ethnicity/thresholds of patients for visiting/calling out GP)

5. Cross cultural factors and ethnicity

- How far do you consider the ethnicity of your patients with asthma affects the way they use your surgery or the hospital for acute asthma care?

6. The admitted patient

- Tell me about your patient who was admitted

(Lead into discussion to clarify events leading up to admission)

- How well do you know them?

- How would you describe your approach to their asthma management?

Interview topics for out of hours deputising doctors

1. Issues relating to out of hours care

- How are patients with acute asthma managed out of hours?

(Probe for degree of "aggressive" management, such as carrying nebulisers, using oral corticosteroids)

- How do you manage a call from a patient with an asthma attack?

(Probe for problems time pressure and need to complete consultation in single visit)

- What factors affect your threshold for referral of patients to hospital?
(Probe for potential for next day review in surgery by GP or partners/practice nurse).

2. Deputising doctors views about asthma patients

- Who do you see as the "experts" in asthma care?

(Probe for differences between different styles of general practice and between general practice and hospital care)

- Who do your patients see as "experts" in asthma care?

(Probe for views of the "best place" to care for acute asthma)

- Are the asthma patients you visit good at assessing the severity of their asthma symptoms and understanding their asthma medication?

(Probe for differences between patients of differing ethnicity/thresholds of patients for visiting/calling out GP)

3. Cross cultural factors and ethnicity

- How does the ethnicity of asthma patients that you visit affect the way they use the deputising service, their surgery, or the hospital for asthma care?

\section{Interview topics for accident and emergency} doctors

1. Issues relating to asthma care

- How are patients with acute asthma managed in Newham accident and emergency department?

(Probe for adherence to protocols, variation from protocols, and reasons, such as perceived higher risk groups)

- What factors affect your threshold for admission to hospital?

(Probe for groups that present particular problems, access to advocates for patients with language difficulties)

- Does knowledge of the patient's general practice and the services it provides affect the way you manage an episode of acute asthma, in particular your threshold for admission?

(Probe for potential for next day review in surgery by GP or partners/practice nurse)

2. Cross cultural factors and ethnicity

- How does the ethnicity of asthma patients who attend the accident and emergency department affect the way they use the service? 